Research Article

\title{
Pathogenicity and genetic profile of oral Porphyromonas species from canine periodontitis
}

\author{
Amanda do Nascimento Silva ${ }^{\mathrm{a}, 1}$, Erica Dorigatti de Avila ${ }^{\mathrm{b}, 1}$, Viviane Nakano ${ }^{\mathrm{a}}$, \\ Mario J. Avila-Campos ${ }^{\mathrm{a}, *}$ \\ a Anaerobe Laboratory, Department of Microbiology, Institute of Biomedical Sciences, University of Sao Paulo - USP, Sao Paulo, SP, Brazil \\ b Department of Dental Materials and Prosthodontics, School of Dentistry of Araraquara, Univ Estadual Paulista - UNESP, Araraquara, SP, Brazil
}

\section{A R T I C L E I N F O}

\section{Keywords:}

Porphyromonas spp.

Periodontal disease

prtC gene

fimA gene

Genetic diversity

\begin{abstract}
A B S T R A C T
Objective: In this study, the presence of the $\operatorname{prtC}$ and fimA genes involved in the pathogenicity of oral Porphyromonas spp. isolated from dogs with periodontitis and healthy, as well as their genetic diversity was investigated.

Design: Thirty-two Beagle dogs, 24 with periodontitis and 8 healthy were evaluated. Subgingival samples from only one gingival site of both groups were collected. Bacteria grown in anaerobiosis were identified by RAPID ID 32A kits. From each strain the respective DNA was obtained and used to genotyping by conventional PCR and AP-PCR.

Results: Dogs with periodontitis harbored 28 P. gulae, 2 P. creviocaricanis, 1 P. cangingivalis and 7 P. macacae; and from healthy dogs, $11 P$. gulae and 5 P. circumdentaria. In $P$. gulae isolated from periodontal dogs the gene prtC was observed in $19(67.85 \%)$ and in 7 (63.63\%) from healthy dogs. $P$. gulae strains from periodontal dogs harbored either the gene fimA I or fimA II; while strains from healthy dogs harbored the gene fimA I, fimA II, fimA III or fimA IV, as well as $1 P$. circumdentaria the gene fimA II. By AP-PCR strains were grouped in different clusters suggesting heterogeneity of these microorganisms.

Conclusions: The results presented herein inform that Porphyromonas spp. isolated from dogs with and without periodontitis harbored the prtC and fimA genes and it could be a role in the establishment of the infectious process.
\end{abstract}

\section{Introduction}

It is well known that periodontitis is a complex infection, in which bacteria are responsible to initiate the immune inflammatory process and the result is a loss of support of the affected teeth (Meyle \& Chapple, 2015). This process is characterized by destruction of the periodontal attachment apparatus, increased bone resorption with loss of crestal alveolar bone, apical migration of the epithelial attachment, and formation of periodontal pockets (Graves, Li, \& Cochran, 2011). Among all oral pathogenic and non-pathogenic microorganisms, species of the genus Porphyromonas are able to invade and to damage the epithelial layer as well as to induce inflammatory responses leading to attachment loss and periodontal destruction (Paster et al., 2001). Porphyromonas gingivalis has been described as a key pathogen in periodontal infections due to the production of different virulence factors, such as gingipain, amino peptidases, invasin, capsule, collagenases, fimbriae, and lipopolysaccharide (Amano, 2003; Jotwani \& Cutler, 2004; Preshaw, Schifferle, \& Walters, 1999).

Fimbriae-producing $P$. gingivalis plays an important role in the attachment and invasion to periodontal tissues (Hamada et al., 1998) and it is critical for promotion of the bacterial infection (Nakagawa, Amano, \& Ohara-Nemoto, 2002). The collagenolytic activity of $P$. gingivalis has been associated to the collagen destruction and progression of periodontitis (Kato, Takahashi, \& Kuramitsu, 1992). This collagenase produced by prtC gene has been described as responsible for cleavage of type I collagen (Wittstock, Schmidt, Flemmig, \& Karch, 2000).

Studies have shown that periodontitis is also common in dogs (Weinberg \& Bral, 1999), leading to bone resorption and tooth loss. In animals, the anaerobic oral microbiota is represented by others important species of Porphyromonas, such as $P$. gulae, $P$. circumdentaria, $P$. creviocaricanis, $P$. casulci, $P$. canoris, $P$. denticanis, $P$. salivosa, $P$. cangingivalis, $P$. canis, $P$. gingivicanis, and $P$. catoniae (Allaker, de Rosayro,

\footnotetext{
* Corresponding author at: Av. Prof. Lineu Prestes 1374, 05508-900 Sao Paulo, SP, Brazil.

E-mail address: mariojac@usp.br (M.J. Avila-Campos).

${ }^{1}$ These authors contributed equally to this work.
} 
Table 1

Nomenclature, oligonucleotide and PCR conditions.

\begin{tabular}{|c|c|c|c|c|}
\hline Primer & Oligonucleotide $5^{\prime} \rightarrow 3^{\prime}$ & Annealing Temperature $\left({ }^{\circ} \mathrm{C}\right)$ & Amplicon (bp) & References \\
\hline Universal & AGA GTT TGA TCC TGG CTC AG GGC TAC CTT GTT ACG ACT T & 58 & 3480 & $\begin{array}{l}\text { Amano, Nakagawa, Okahashi, and Hamada, } \\
2004\end{array}$ \\
\hline prtC & $\begin{array}{l}\text { CGA GAT CGG AGT AGA AGT GCA TC CCA CGG TTT GCA GTT CGT } \\
\text { ATC G }\end{array}$ & 55 & 815 & Odell et al. (1999) \\
\hline fimA I & $\begin{array}{l}\text { CTG TGT GTT TAT GGC AAA CTT C AC CCC GCT CCC TGT ATT CCG } \\
\text { A }\end{array}$ & 58 & 392 & Amano et al. (2004) \\
\hline fimA II & $\begin{array}{l}\text { ACA ACT ATA CTT ATG ACA ATG G AAC CCC GCT CCC TGT ATT } \\
\text { CCG A }\end{array}$ & 58 & 257 & Amano et al. (2004) \\
\hline fimA III & $\begin{array}{l}\text { ATT AC ACCT ACA CAG GTG AGG C AAC CCC GCT CCC TGT ATT } \\
\text { CCG A }\end{array}$ & 58 & 247 & Amano et al. (2004) \\
\hline fimA IV & $\begin{array}{l}\text { CTA TTC AGG TGC TAT TCA CCA A AAC CCC GCT CCC TGT ATT CCG } \\
\text { A }\end{array}$ & 58 & 251 & Amano et al. (2004) \\
\hline $\operatorname{fim} A \mathrm{~V}$ & $\begin{array}{l}\text { AAC ACC AGT CTC CTT GAC AGT G TAT TGG GGG TCG AAC GTT } \\
\text { ACT GTC }\end{array}$ & 58 & 462 & Nakagawa et al. (2002) \\
\hline OPA-03 & AGT CAG CCA C & 42 & - & Chen and Slots (1994) \\
\hline OPA-05 & AGG GGT CTTG & 42 & - & Chen and Slots (1994) \\
\hline OPA-13 & CGG CAC CCA C & 42 & - & Chen and Slots (1994) \\
\hline OPA-17 & GAC CGT CTT GT & 42 & - & Chen and Slots (1994) \\
\hline
\end{tabular}

Young, \& Hardie, 1997; Hardham, Dreier, Wong, Sfintescu, \& Evans, 2005; Isogai, Kosako, Benno, \& Isogai, 1999). Porphyromonas gulae is a gram-negative, black-pigmented producing, and is considered the commonly species detected in subgingival biofilm of dogs displaying periodontitis (Kato et al., 2011). Similarly to $P$. gingivalis the fimbriae is an important cell structure involved in the adherence and invasion of host's cells, and stimulates the production of inflammatory cytokines by macrophages and fibroblasts. This adhesive ability is considered to be a major pathogenic characteristic that causes periodontal tissue destruction (Amano, Nakagawa, Kataoka, Morisaki, \& Hamada, 1999; Sasaki, Watanabe, Toyama, Koyata, \& Hamada, 2015).

On the other hand, little is known about the presence of Porphyromonas spp. isolated from dogs carrying the $\operatorname{prtC}$ gene, as well as its relationship with the canine periodontitis. Since pathogenic bacteria from animal origin, particularly dogs, may be transferred to people through bites, for example; and considering their involvement in human and animal periodontal disease; this study, was performed to determine the presence of the $\operatorname{prtC}$ and $\operatorname{fim} A$ genes in oral Porphyromonas spp. isolated from dogs with and without periodontal disease, as well as, the genetic diversity of these species by using an APPCR technique.

\section{Materials and methods}

\subsection{Animal study design}

Subgingival biofilm samples were collected from thirty-two Beagle dogs of 7-months to 10-years-old at the School of Veterinary Medicine and Zootechny of the University of Sao Paulo (Sao Paulo, SP, Brazil). Dogs were grouped in: (1) Eight dogs without periodontitis, and (2) 24 dogs with periodontitis. As inclusion criteria, only the animals had received no antibiotic treatment within the previous three months of the sample collection. Prior to collection, the animals with periodontitis were examined in relation to clinical conditions: degree of gingival inflammation, supragingival plaque level, probing pocket depths ( $5 \mathrm{~mm}$ ), bleeding on probing, tooth mobility, and alveolar bone loss.

The animals underwent anesthesia with a mixture of propofol $(2 \mathrm{mg} / \mathrm{kg}$ ) and diazepam $(5.5 \mathrm{mg} / \mathrm{kg}$ ) administered via intramuscular injection (Senhorinho et al., 2011). Briefly, supragingival biofilms were removed with sterile gauze to avoid any contamination of the paper points. Then, subgingival samples from only one gingival site of both groups were collected with two fine sterile paper points (N. 30, Tanariman Ind Ltd, AM, Brazil), introduced into the apical region for $60 \mathrm{~s}$. Paper points were then placed into VMGA III transport medium and processed within $4 \mathrm{~h}$ of collection.
The protocols used in this study were approved by the Ethics Committee for Animal Experimentation at the Institute of Biomedical Science/USP (116/CEEA), and followed all recommendations of the ARRIVE (Animal Research: Reporting In Vivo Experiments) guidelines for the execution and submission of studies in animals.

\subsection{DNA extraction, PCR assay and AP-PCR genotyping}

Bacteria were isolated on Brucella blood agar supplemented with hemine $(0.5 \mu \mathrm{g} / \mathrm{ml})$ and menadione $(0.1 \mu \mathrm{g} / \mathrm{ml})$, at $37^{\circ} \mathrm{C}$, under anaerobic conditions $\left(10 \% \mathrm{CO}_{2} / 90 \% \mathrm{~N}_{2}\right)$, and identified in accordance with Jousimies-Somer et al. (2002) or by RAPID ID 32A kits (bioMérieux) according to the manufacturer's instructions. The broth bacterial cultures were centrifuged at $14.000 \mathrm{~g}$ for $10 \mathrm{~min}$ to spin down the pellet and used to DNA extraction. The total genomic DNA was isolated by Easy-DNA commercial kit (Invitrogen do Brasil, Ltd, Sao Paulo, SP, Brazil) and the concentration of bacterial DNA determined with a spectrophotometer $\left(\mathrm{OD}_{260 \mathrm{~nm}}\right)$.

PCR Amplifications were performed as described: each $25 \mu \mathrm{L}-\mathrm{PCR}$ contained 1 X PCR buffer, $2.5 \mathrm{mM} \mathrm{MgCl}_{2}, 20 \mu \mathrm{M}$ dNTP (Invitrogen), $0.5 \mathrm{U}$ Platinum Taq DNA polymerase (Invitrogen), $0.4 \mu \mathrm{M}$ of each primer (Table 1) (Chen \& Slots, 1994; Odell, Baumgartner, Xia, \& David, 1999) and $1 \mu \mathrm{L}$ of DNA. The cycle conditions were optimized according to the gene. For prtC gene, denaturation 1 cycle of $94^{\circ} \mathrm{C}(5 \mathrm{~min})$; amplification, for 33 cycles of $94{ }^{\circ} \mathrm{C}(1 \mathrm{~min}), 55^{\circ} \mathrm{C}(1 \mathrm{~min}), 72{ }^{\circ} \mathrm{C}(1 \mathrm{~min})$; and 1 cycle of $72{ }^{\circ} \mathrm{C}(10 \mathrm{~min})$. For fimA gene detection the same PCR conditions were used, but with 30 cycles of $94^{\circ} \mathrm{C}(30 \mathrm{~s}), 58^{\circ} \mathrm{C}(30 \mathrm{~s})$, and $72{ }^{\circ} \mathrm{C}(30 \mathrm{~s})$. Combinations were used in all PCR reactions and amplifications were performed in a thermal cycler (Perkin Elmer Amp PCR System 2400).

In order to investigate the AP-PCR genotyping, four arbitrary primers OPA-03, OPA-05, OPA-13 and OPA-17 (Table 1) and $10 \mu \mathrm{L}$ of DNA were used, as mentioned above. Conditions were further optimized, as follow: denaturation 1 cycle of $94^{\circ} \mathrm{C}$ ( $5 \mathrm{~min}$ ); amplification, for 35 cycles of $94{ }^{\circ} \mathrm{C}(1 \mathrm{~min}), 42{ }^{\circ} \mathrm{C}(2 \mathrm{~min}), 72{ }^{\circ} \mathrm{C}(2 \mathrm{~min})$; and 1 cycle of $72{ }^{\circ} \mathrm{C}(10 \mathrm{~min})$. From all the resulting PCR products, twenty microlitres of each amplification product were evaluated by electrophoresis in $1.0 \%$ agarose gel. Reference strains $P$. gingivalis ATCC 33277 and $F$. nucleatum ATCC 10953 were used as control.

\subsection{Statistic analysis}

Pairwise similarities were computed by the package NTSYS program (Applied Biostatistics, Inc. version 1.7) program using the Dicce coefficient of similarity and unweighted pair group method using arithmetic 
Table 2

Presence of the prtC and fimA genes in Porphyromonas strains from dogs with and without periodontitis.

\begin{tabular}{|c|c|c|c|c|c|c|}
\hline \multirow[b]{2}{*}{ Origin Strains (no.) } & \multicolumn{6}{|c|}{ Genes } \\
\hline & $\operatorname{prtC}$ & $\operatorname{fim} A \mathrm{I}$ & fimA II & fimA III & fimA IV & $\operatorname{fim} A \mathrm{~V}$ \\
\hline \multicolumn{7}{|l|}{ Dogs with Periodontitis } \\
\hline \multicolumn{7}{|l|}{ P. gulae $(\mathrm{n}=28)$} \\
\hline D1, D4, D7, D20, D22 & + & + & - & - & - & - \\
\hline D3 & + & - & + & - & - & - \\
\hline $\begin{array}{c}\text { D2, D8, D12, D21, D25, } \\
\text { D26, D27, D28, D30, } \\
\text { D32, D33, D34, D35 }\end{array}$ & + & - & - & - & - & - \\
\hline D9, D23, D29 & - & + & - & - & - & - \\
\hline $\begin{array}{l}\text { D5, D6, D10, D11, D24, } \\
\text { D36 }\end{array}$ & - & - & - & - & - & - \\
\hline \multicolumn{7}{|l|}{ P. creviocaricanis $(\mathrm{n}=2)$} \\
\hline D37, D38 & - & - & - & - & - & - \\
\hline \multicolumn{7}{|l|}{ P. cangingivalis $(\mathrm{n}=1)$} \\
\hline D31 & + & - & - & - & - & - \\
\hline \multicolumn{7}{|l|}{ P. macacae $(\mathrm{n}=7)$} \\
\hline $\begin{array}{l}\text { D13, D14, D15, D16, D17, } \\
\text { D18, D19 }\end{array}$ & - & - & - & - & - & - \\
\hline \multicolumn{7}{|l|}{ Healthy Dogs } \\
\hline \multicolumn{7}{|l|}{ P. gulae $(\mathrm{n}=11)$} \\
\hline S2 & + & + & - & + & + & - \\
\hline S1 & + & - & - & + & + & - \\
\hline S3 & + & + & + & - & + & - \\
\hline S4 & + & - & + & - & - & - \\
\hline S5, S6 & + & + & + & - & - & - \\
\hline S7 & + & - & - & - & - & - \\
\hline S8, S10, S12, S13 & - & - & - & - & - & - \\
\hline \multicolumn{7}{|l|}{ P. circumdentaria $(\mathrm{n}=5)$} \\
\hline S11 & - & - & + & - & - & - \\
\hline $\mathrm{S} 16$ & + & - & - & - & - & - \\
\hline S9, S14, S15 & - & - & - & - & - & - \\
\hline \multicolumn{7}{|l|}{ Reference strains } \\
\hline P. gingivalis ATCC 33277 & + & + & - & - & - & - \\
\hline F. nucleatum ATCC 10953 & - & - & - & - & - & - \\
\hline
\end{tabular}

Presence (+); absence (-).

averages (UPGMA) clustering.

\section{Results}

Fifty-four strains were isolated and identified from 24 dogs with periodontitis (38 strains) and from eight healthy dogs (16 strains) (Table 2). The prtC gene was detected in $19(67.86 \%)$ of $28 P$. gulae strains, and in $1 P$. cangingivalis isolated from dogs with periodontitis. Neither two $P$. creviocaricanis nor seven $P$. macacae strains harbored that gene. Of the 16 strains from healthy dogs, 7 (63.64\%) P. gulae and $1 P$. circumdentaria harbored the $p r t C$ gene. The fimA I gene was observed only in eight $P$. gulae strains from periodontitis and in four strains from healthy dogs. The presence of fimA II gene was noted in 1 $P$. gulae from periodontitis, and in $4 P$. gulae and $1 P$. circumdentaria from healthy dogs. Interestingly, the fimA III and fimA IV were not observed in $P$. gulae strain from periodontal dogs, but both genes were noted in $2 P$. gulae, and fimA IV in another strain isolated from dogs without periodontitis. Moreover, neither periodontal nor healthy dogs harbored strains with the fimA V gene (Table 2). Double or triple bacterial associations with fimbriae types were observed only in strains isolated from healthy dogs. Reference strains $P$. gingivalis ATCC 33277 harbored the prtC and fimA I genes, and F. nucleatum ATCC 10953 did not harbor both genes.

In Fig. 1 is observed the genetic analysis of the 38 Porphyromonas strains. A High degree of DNA polymorphism was detected with OPA03 primer, which produced clear bands and a good bacterial distribution showing the presence of 15 clusters with $50 \%$ of similarity. In addition, the primers OPA-05, OPA-13 and OPA 17, revealed weak amplification bands. These bands were not constantly detected by visual inspection, and were not considerate in this analysis. The presence or absence of $\operatorname{prtC}$ and fimA genes did not show any relationship with the clusters. The genotyping of the strains by AP-PCR produced from 4000 to 400 bp DNA fragments, with 15 different genetic profiles in strains isolated from dogs with and without periodontitis. In addition, in Fig. 1 can also be observed three main groups: group A, harbored only strains isolated from periodontitis including $P$. gingivalis ATCC 33277 (P.g ATCC); group B, strains isolated from dogs with and without disease, and group $\mathrm{C}$, containing only strains from healthy dogs. The cluster IX was formed for two sub-group containing $P$. macacae strains isolated from dogs with periodontitis. These strains showed $100 \%$ of similarity. Strains isolated from healthy dogs, were grouped from XI to XV. The cluster XIV grouped three $P$. circumdentaria (P.c) with $100 \%$ of similarity. Some strains of Porphyromonas and F. nucleatum ATCC 10953 did not amplify fragments.

\section{Discussion}

Dog periodontitis-related bacterial species have been found in human oral cavity and are involved with aggressiveness of the disease. Similarly to the human periodontal disease, species of Porphyromonas are also important etiological agents in dog oral infections (Pihlstrom, Michalowicz, \& Johnson, 2005), and among them, P. gulae is considered the most prevalent (Kato et al., 2011). In order to investigate the presence of black-pigmented anaerobic bacteria from animal origin and their virulence factors involved in periodontal disease, we determined the presence of Porphyromonas species in dogs with and without periodontal disease. The genetic diversity of these species isolated from periodontal and healthy dogs were demonstrated by AP-PCR analysis.

Porphyromonas gulae from dogs with periodontitis were significantly present in higher number than those of the healthy group. Furthermore, we demonstrated that bacterial species isolated from periodontal dogs displayed both prtC and fimA genes, that promote the adherence and colonization to the host's tissues. Importantly, we also found a high level of polymorphism among the Porphyromonas spp., which might reflect the potential of virulence and its involvement with periodontal disease. This is an important finding since competition among clones might select more resistant clones able to survival in the human host.

Fimbriae are also considered to be critical factors that mediate bacterial interactions in the adherence and invasion to the host's cells. FimA is encoded by the fimA gene and its virulence is related to the genetic variation. The presence of $P$. gingivalis fimA genotypes II and IV have been shown to be significantly more prevalent than other genotypes in human chronic marginal periodontitis processes (Amano et al., 2000; Feng et al., 2014). The pathogenicity of the various fimA genotypes has also been evaluated in animal models. Strains fimA genotypes II, Ib or IV appear to cause severe infectious symptoms and inflammatory changes, when compared to strains fimA genotypes I and III (Amano et al., 1999; Nakano et al., 2004). Additionally, studies on the pathogenic potential of Porphyromonas spp. have shown that fimA genotypes II are prevalent in patients with aggressive periodontitis (Miura, Hamachi, Fujise, \& Maeda, 2005). These results support the proposal that $P$. gulae could be considered as a possible risk factor for the periodontitis development (Senhorinho et al., 2011).

In line with previous studies, our findings show the presence of Porphyromonas spp. fimA genotype I in both groups of dogs with periodontitis and healthy, suggesting no association between that genotype and the disease evolution. On the other hand, fimA genotype II associated with human aggressive oral diseases was found in only one dog with periodontitis. These results suggest that Porphyromonas spp. harboring genes, such as $p r t C$ and fim $A$ can be pathogenic to animals, but it might not be true to produce an oral disease in humans, in accordance with (Amano et al., 2000). Some studies affirm that it is difficult for oral bacteria from canine origin to survive and colonize the human oral 


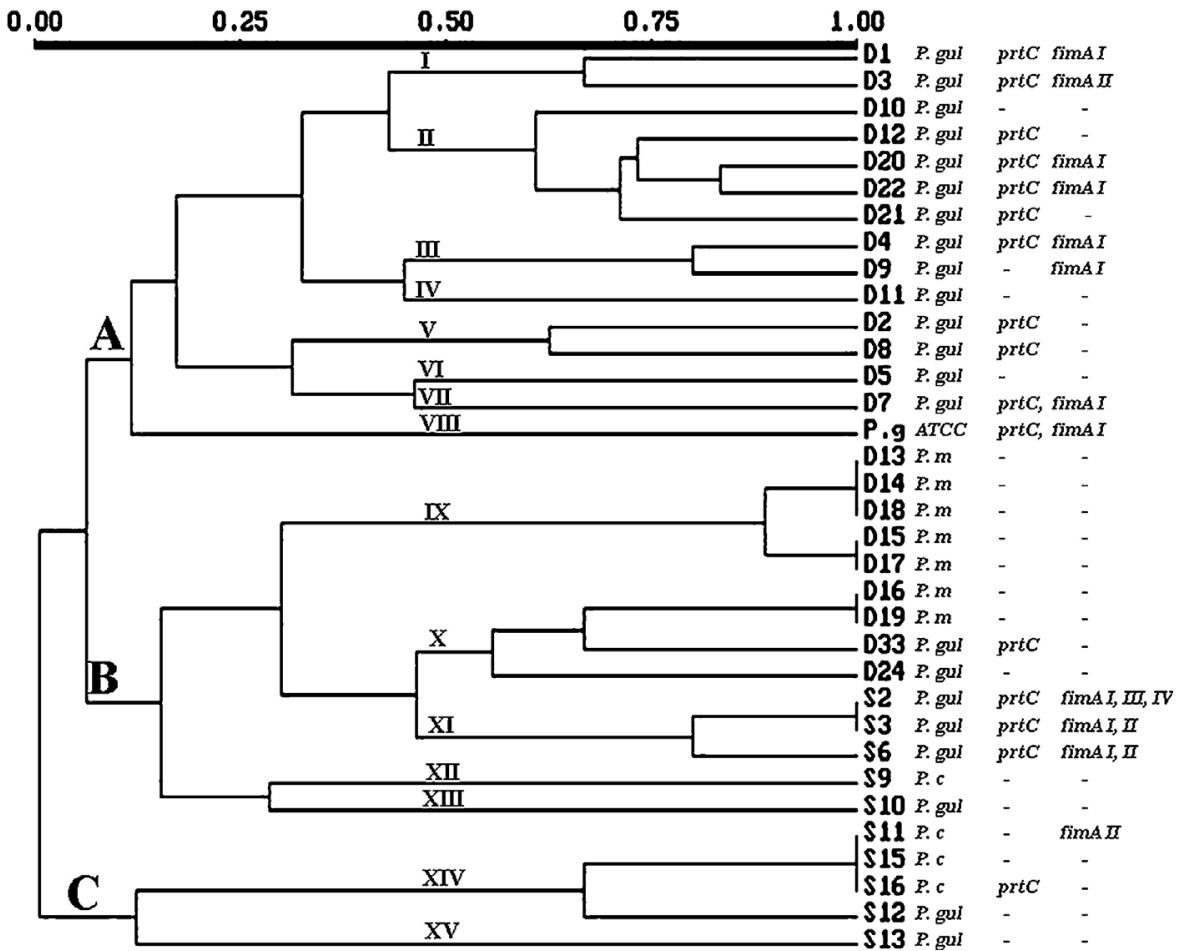

Fig. 1. Dendrogram showing the genetic profile of oral Porphyromonas strains isolated from dogs with and without periodontitis. (D) Strains from dogs with periodontitis; (S) strains from healthy dogs; $(-/+)$ absence/presence of genes; (prtC and fimA) presence of the genes; (P. gul) P. gulae; (P. m) $P$. macacae; $(P$. c) $P$. circumdentaria; and (ATCC) $P$. gingivalis ATCC 33277. cavity (Oh et al., 2015) due to the physiological differences between the two environments, such as: difference of $\mathrm{pH}$ (Li \& Bowden, 1994) and by the fact that humans brush their teeth removing the supra- and subgingival bacterial biofilms. In addition, when canine oral bacteria are transmitted to the human oral cavity, these microorganisms begin an ecological competition with the human resident oral microbiota, and it can influence the expression of some virulence factor for the initiation of a disease (Senhorinho et al., 2012). The bacterial dynamic relationship in different microbial ecosystem needs more studies.

Our results show that periodontal dogs harbored strains fimA I and fimA II, and healthy dogs harbored fimA I, fimA II, fimA III, and fimA IV. This result suggests that species of Porphyromonas with genotypes fim $A$ III and fimA IV are not implicated in periodontal disease of dogs. Since in humans, the presence of $P$. gingivalis harboring the fim $A$ gene may be associated with the severity of the periodontitis; it is possible that $P$. gulae with the genotype fim $A$ may also be associated with the pathogenesis of periodontitis in dogs. Studies have shown that the presence of long fimbriae observed in $P$. gingivalis serve to mediate the co-adhesion with other bacteria, such as Actinomyces viscosus, Treponema denticola and Streptococcus oralis (Goulbourne \& Ellen, 1991; Hashimoto, Ogawa, Asai, Takai, \& Ogawa, 2003; Maeda et al., 2004).

The FimA protein produced by $P$. gulae has been classified into genotypes A-C. The bacterial detection with different fimA genotypes is considered a risk factor to the periodontitis development (Maeda et al., 2004). In addition, differences in the fimbriae protein from $P$. gulae are related to the level of aggressiveness determined by their bone destruction capacity (Nomura et al., 2012). The $41-\mathrm{kDa}$ fimbriae protein is able to induce the osteoclast differentiation as well as the inflammatory cytokine production by macrophages, in murine model, as well as it was similar to LPS in the osteoclast activation in periodontal diseases (Nomura et al., 2012). Thus, the presence of specific fimbriae proteins in $P$. gulae can explain the divergent results observed in different studies, and it might be useful to understand the association of the presence of fimA genotypes with either oral health or disease.

In order to examine the potential role of the bacterial collagenases in oral diseases, we investigated the presence of the $\operatorname{prtC}$ gene in oral Porphyromonas isolated from dogs with and without periodontal disease. Collagenase is a potential virulence factor, which is expressed by
P. gingivalis associated with periodontal disease (Odell et al., 1999), and it is suggested that prtC gene-positive Porphyromonas spp. plays an important role in the progression of periodontitis; however, studies of this enzyme produced by $P$. gulae on host's cells need to be performed. A limitation of this study was the sample size and the differences on number of dogs in both with and without disease groups. Furthermore, we selected dogs with a large age range, and since the total number of bacterial species detected in these animals was positively correlated with their chronological age, this variation could be interfered our findings (Harvey, Shofer, \& Laster, 1994).

Further studies focusing the understanding of the relationship among the bacterial transmission, bacterial genes and protein expression in oral environment, and the relationship with oral disease of pathogenic oral bacteria from dogs to humans might be important to help us to better understand the complex oral microbial ecosystem. In conclusion, the high level of Porphyromonas spp. from animal origin takes many paths to a reinfection of humans, due to colonized or infected pets might influence the pathogenesis of disease in humans. Our findings strongly suggest that the colonization and adaptation of Porphyromonas spp. from dogs in human oral cavity is a possible fact. Also, these results allow us to correlate the presence of the $\operatorname{prtC}$ and fim $A$ genes, particularly fimA I and fimA II, with periodontal disease in dogs.

\section{Conflict of interests}

The authors declare that they have no competing interests.

\section{Acknowledgements}

The authors would like to thank Mrs. Marcia Harumi Fukugaiti for her technical support. This study was supported by FAPESP No. 2013/ 13652-6.

\section{References}

Allaker, R. P., de Rosayro, R., Young, K. A., \& Hardie, J. (1997). Prevalence of

Porphyromonas and Prevotella species in the dental plaque of dogs. Veterinary Record, $140,147-148$.

Amano, A., Nakagawa, I., Kataoka, K., Morisaki, I., \& Hamada, S. (1999). Distribution of 
Porphyromonas gingivalis strains with fimA genotypes in periodontitis patients. Journal of Clinical Microbiology, 37, 1426-1430.

Amano, A., Kuboniwa, M., Nakagawa, I., Akiyama, S., Morisaki, I., \& Hamada, S. (2000). Prevalence of specific genotypes of Porphyromonas gingivalis fimA and periodontal health status. Journal of Dental Research, 79, 1664-1668.

Amano, A., Nakagawa, I., Okahashi, N., \& Hamada, N. (2004). Variations of Porphyromonas gingivalis fimbriae in relation to microbial pathogenesis. Journal of Periodontal Research, 39, 136-142.

Amano, A. (2003). Molecular interaction of Porphyromonas gingivalis with host cells: Implication for the microbial pathogenesis of periodontal disease. Journal of Periodontology, 74, 90-96.

Chen, C., \& Slots, J. (1994). Clonal analysis of Porphyromonas gingivalis by the arbitrarily primed polymerase chain reaction. Oral Microbiology and Immunology, 9, 99-103.

Feng, X., Zhang, L., Xu, L., Meng, H., Lu, R., Chen, Z., et al. (2014). Detection of eight periodontal microorganisms and distribution of Porphyromonas gingivalis fimA genotypes in Chinese patients with aggressive periodontitis. Journal of Periodontology, 85, 150-159.

Goulbourne, P. A., \& Ellen, R. P. (1991). Evidence that Porphyromonas (Bacteroides) gingivalis fimbriae function in adhesion to Actinomyces viscosus. Jounal of Bacteriology, 173, 5266-5274.

Graves, D. T., Li, J., \& Cochran, D. L. (2011). Inflammation and uncoupling as mechanisms of periodontal bone loss. Journal of Dental Research, 90, 143-153.

Hamada, S., Amano, A., Kimura, S., Nakagawa, I., Kawabata, S., \& Morisaki, I. (1998). The importance of fimbriae in the virulence and ecology of some oral bacteria. Oral Microbiology and Immunology, 13, 129-138.

Hardham, J., Dreier, K., Wong, J., Sfintescu, C., \& Evans, R. T. (2005). Pigmentedanaerobic bacteria associated with canine periodontitis. Veterinary Microbiology, 106, $119-128$.

Harvey, C. E., Shofer, F. S., \& Laster, L. (1994). Association of age and body weight with periodontal disease in North American dogs. Journal of Veterinary Dentistry, 11, 94-105.

Hashimoto, M., Ogawa, S., Asai, Y., Takai, Y., \& Ogawa, T. (2003). Binding of Porphyromonas gingivalis fimbriae to Treponema denticola dentilisin. FEMS Microbiology Letters, 226, 267-271.

Isogai, H., Kosako, Y., Benno, Y., \& Isogai, E. (1999). Ecology of genu: Porphyromonas in canine periodontal disease. Zentralblatt für Veterinärmedizin. Reihe B. Journal of Veterinary Medicine. Series B, 46, 467-473.

Jotwani, R., \& Cutler, C. W. (2004). Fimbriated Porphyromonas gingivalis is more efficient than fimbria-deficient Porphyromonas gingivalis in entering human dendritic cells in vitro and induces an inflammatory Th1 effector response. Infection and Immunity, 72, $1725-1732$.

Jousimies-Somer, H., Summanen, P., Citron, D. M., Baron, E. J., Wexler, H. M., \& Finegold, S. M. (2002). Wadsworth-KTL anaerobic bacteriology manual (6th ed.). Belmont, CA: Star Publishing.

Kato, T., Takahashi, N., \& Kuramitsu, H. K. (1992). Sequence analysis and characterization of the Porphyromonas gingivalis prtC gene, which expresses a novel collagenase activity. Journal of Bacteriology, 174, 3889-3895.

Kato, Y., Shirai, M., Murakami, M., Mizusawa, T., Hagimoto, A., Wada, K., et al. (2011). Molecular detection of human periodontal pathogens in oral swab specimens from dogs in Japan. Journal of Veterinary Dentistry, 28, 84-89.
Li, Y. H., \& Bowden, G. H. (1994). The effect of environmental pH and fluoride from the substratum on the development of biofilms of selected oral bacteria. Journal of Dental Research, 73, 1615-1626.

Maeda, K., Nagata, H., Yamamoto, Y., Tanaka, M., Tanaka, J., Minamino, N., et al. (2004). Glyceraldehyde-3-phosphate dehydrogenase of Streptococcus oralis functions as a coadhesin for Porphyromonas gingivalis major fimbriae. Infection and Immunity, 72, 1341-1348.

Meyle, J., \& Chapple, I. (2015). Molecular aspects of the pathogenesis of periodontitis. Periodontology 2000, 69, 7-17.

Miura, M., Hamachi, T., Fujise, O., \& Maeda, K. (2005). The prevalence and pathogenic differences of Porphyromonas gingivalis fimA genotypes in patients with aggressive periodontitis. Journal of Periodontal Research, 40, 147-152.

Nakagawa, I., Amano, A., \& Ohara-Nemoto, Y. (2002). Identification of a new variant of fimA gene of Porphyromonas gingivalis and its distribution in adults and disabled populations with periodontitis. Journal of Periodontal Research, 37, 425-432.

Nakano, K., Kuboniwa, M., Nakagawa, I., Yamamura, T., Nomura, R., Okahashi, N., et al. (2004). Comparison of inflammatory changes caused by Porphyromonas gingivalis with distinct fimA genotypes in a mouse abscess model. Oral Microbiology and Immunology, 19, 205-209.

Nomura, R., Shirai, M., Kato, Y., Murakami, A., Nakano, K., Hirai, N., et al. (2012). Diversity of fimbrillin among Porphyromonas gulae clinical isolates from Japanese dogs. Journal of Veterinary Medical Science, 74, 885-891.

Odell, L. J., Baumgartner, J. C., Xia, T., \& David, L. L. (1999). Survey for collagenase gene prtC in Porphyromonas gingivalis and Porphyromonas endodontalis isolated from endodontic infections. Journal of Endodontic, 25, 555-558.

Oh, C., Lee, K., Cheong, Y., Lee, S.-W., Park, S.-Y., Song, C.-S., et al. (2015). Comparison of the oral microbiomes of canines and their owners using next-generation sequencing. Public Library of Science, 10, e0131468.

Paster, B. J., Boches, S. K., Galvin, J. L., Ericson, R. E., Lau, C. N., Levanos, V. A., et al. (2001). Bacterial diversity in human subgingival plaque. Journal of Bacteriology, 183, 3770-3783.

Pihlstrom, B. L., Michalowicz, B. S., \& Johnson, N. W. (2005). Periodontal diseases. Lancet, 366, 1809-1820.

Preshaw, P. M., Schifferle, R. E., \& Walters, J. D. (1999). Porphyromonas gingivalis lipopolysaccharide delays human polymorphonuclear leukocyte apoptosis in vitro. Journal of Periodontal Research, 34, 197-202.

Sasaki, H., Watanabe, K., Toyama, T., Koyata, Y., \& Hamada, N. (2015). Porphyromonas gulae $41-\mathrm{kDa}$ fimbriae induced osteoclast differentiation and cytokine production. Journal of Veterinary Medical Science, 77, 265-271.

Senhorinho, G. N., Nakano, V., Liu, C., Song, Y., Finegold, S. M., \& Avila-Campos, M. J. (2011). Detection of Porphyromonas gulae from subgingival biofilms of dogs with and without periodontitis. Anaerobe, 17, 257-258.

Senhorinho, G. N., Nakano, V., Liu, C., Song, Y., Finegold, S. M., \& Avila-Campos, M. J. (2012). Occurrence and antimicrobial susceptibility of Porphyromonas spp. and Fusobacterium spp. in dogs with and without periodontitis. Anaerobe, 18, 381-385.

Weinberg, M. A., \& Bral, M. (1999). Laboratory animal models in periodontology. Journal of Clinical Periodontology, 26, 335-340.

Wittstock, M., Schmidt, H., Flemmig, T. F., \& Karch, H. (2000). Heterogeneity of the prtC gene of Porphyromonas gingivalis. Oral Microbiology and Immunology, 15, 33-39. 